\title{
Links between Indo-Pacific climate variability and drought in the Monsoon Asia Drought Atlas
}

\author{
Caroline C. Ummenhofer · Rosanne D. D'Arrigo • \\ Kevin J. Anchukaitis · Brendan M. Buckley • \\ Edward R. Cook
}

Received: 5 December 2011 / Accepted: 12 July 2012

(C) Springer-Verlag 2012

\begin{abstract}
Drought patterns across monsoon and temperate Asia over the period 1877-2005 are linked to IndoPacific climate variability associated with the El NiñoSouthern Oscillation (ENSO) and the Indian Ocean Dipole (IOD). Using the Monsoon Asia Drought Atlas (MADA) composed of a high-resolution network of hydroclimatically sensitive tree-ring records with a focus on the JuneAugust months, spatial drought patterns during El Niño and IOD events are assessed as to their agreement with an instrumental drought index and consistency in the drought response amongst ENSO/IOD events. Spatial characteristics in drought patterns are related to regional climate anomalies over the Indo-Pacific basin, using reanalysis products, including changes in the Asian monsoon systems, zonal Walker circulation, moisture fluxes, and precipitation. A weakening of the monsoon circulation over the Indian subcontinent and Southeast Asia during El Niño events, along with anomalous subsidence over monsoon Asia and reduced moisture flux, is reflected in anomalous drought conditions over India, Southeast Asia and Indonesia. When an IOD event co-occurs with an El Niño, severe drought conditions identified in the MADA for Southeast Asia, Indonesia, eastern China and central Asia are associated with a weakened South Asian monsoon, reduced moisture flux over China, and anomalous divergent flow and subsidence over Indonesia. Insights into the relative influences of Pacific and Indian Ocean variability
\end{abstract}

C. C. Ummenhofer $(\square)$

Climate Change Research Centre, University of New South

Wales, Kensington, Sydney, NSW 2052, Australia

e-mail: c.ummenhofer@unsw.edu.au

R. D. D'Arrigo - K. J. Anchukaitis · B. M. Buckley · E. R. Cook Tree-Ring Laboratory, Lamont-Doherty Earth Observatory of Columbia University, Palisades, NY 10964, USA for Asian monsoon climate on interannual to decadal and longer timescales, as recorded in the MADA, provide a useful tool for assessing long-term changes in the characteristics of Asian monsoon droughts in the context of IndoPacific climate variability.

Keywords Climate variability - Indo-Pacific - Asian monsoon · Drought · El Niño-Southern Oscillation · Indian Ocean dipole · Tree rings · MADA

\section{Introduction}

Severe droughts affecting extensive areas across monsoon Asia and potentially lasting several years to decades have recently gained increasing attention with the advent of improved paleoclimate reconstructions across the region. A network of relatively high-resolution paleoclimate proxy reconstructions from tree rings covering the last millennium (Cook et al. 2010, and references therein) has opened new possibilities for understanding variability in hydrological conditions across monsoon and temperate Asia on interannual, decadal to centennial timescales and links to global climate. As such, it offers an extended climatic record across a densely populated region, which is reliant on monsoon rainfall but has limited coverage of instrumental climate data over extended periods (Wahl and Morrill 2010), as well as across remote, sparsely-populated regions in central Asia with limited observations.

Reliance on the monsoon for rain-fed agriculture make the agrarian-based societies of monsoon Asia particularly vulnerable to small deviations in rainfall during the boreal summer monsoon. Widespread socioeconomic impacts can result from a weakening or even failure of the monsoon rains: For example, the economic impact of the $19 \%$ drop 
in Indian monsoon rainfall in 2002 was on the order of billions of dollars (Gadgil et al. 2004). Over the last millennium, profound societal changes, including the demise of the Khmer civilization in Cambodia (Buckley et al. 2010), civil unrest at the end of the Tang, Yuan and Ming Dynasties in China (Zhang et al. 2008), and societal reorganizations across Southeast Asia in the mid-eighteenth century (Cook et al. 2010) have also been associated with severe drought episodes across monsoon Asia.

Extensive droughts across monsoon Asia over the past centuries, resulting from variations in the strength and position of the monsoon systems, have been linked to a range of factors, including the Pacific Ocean's leading mode of variability on interannual timescales, the El NiñoSouthern Oscillation (ENSO; Charles et al. 1997; Cook et al. 2010), and on decadal timescales, the Pacific Decadal Oscillation (PDO; Krishnan and Sugi 2003; Buckley et al. 2007) and/or the Interdecadal Pacific Oscillation (IPO; Meehl and $\mathrm{Hu}$ 2006), volcanic (D'Arrigo et al. 2009; Anchukaitis et al. 2010) and solar forcing (Zhang et al. 2008), amongst others. There are indications that Indian Ocean conditions play an important role as well (e.g., Buckley et al. 2007; D'Arrigo et al. 2008; Sinha et al. 2011), but little research has focused on the Indian Ocean in this context. Here, we highlight the mechanisms, by which Indo-Pacific variability impacts monsoon Asian climate, using reanalysis data and a multi-century drought atlas based on hydroclimatically-sensitive dendrochronologies across monsoon Asia, the Monsoon Asia Drought Atlas (MADA; Cook et al. 2010).

The latest view of monsoon dynamics considers regional monsoon systems to be manifestations of the seasonally migrating ITCZ, and as such ultimately part of a global monsoon (Gadgil 2003; Sinha et al. 2011, and references therein), where feedbacks between the tropical circulation and large-scale extratropical eddies are critical for monsoon development (Bordoni and Schneider 2008). This contrasts the traditional view of the monsoon as a giant sea breeze, driven by a land-sea thermal contrast. However, on a regional scale, while not crucial for its existence, the temperature contrasts can still influence monsoon variability. As such, variability in the Asian monsoon is linked to regional climate variations, such as sea surface temperatures (SST) of the Pacific and Indian Oceans, and Eurasian snow cover and soil moisture (Wahl and Morrill 2010). In particular, Pacific Ocean variability associated with ENSO has a profound impact on the Asian monsoon systems (e.g., Sikka 1980; Rasmusson and Carpenter 1983; Ropelewski and Halpert 1987): during El Niño events, the eastward shift in the zonal Walker circulation and ensuing anomalous subsidence over monsoon Asia leads to a weakening of the Indian (e.g., Ashok et al. 2004; Krishna Kumar et al. 2006) and South Asian (Goswami and Xavier
2005; Buckley et al. 2010), and strengthening of the East Asia-Western North Pacific (e.g., Chou et al. 2003; Feng and $\mathrm{Hu}$ 2004) monsoons. Drought reconstructions from hydroclimatically sensitive tree-rings across monsoon Asia reflect this relationship, with drought periods linked to ENSO for example in northern India (Yadav 2011), Thailand (Buckley et al. 2007), Cambodia (Buckley et al. 2010), Indonesia (D'Arrigo et al. 2006), and Mongolia (Davi et al. 2010). In the MADA, the leading mode of the reconstructed Palmer Drought Severity Index (PDSI) across monsoon Asia, accounting for $11.5 \%$ of the total variability, is characterized by anomalous dry conditions over the Indian subcontinent and Southeast Asia, wet anomalies for central Asia (Tibetan Plateau, Pamir and Tien Shan Mountains) and eastern China, and SST anomalies reminiscent of El Niño events (Cook et al. 2010).

Reorganization of the atmospheric circulation over the Indian Ocean region, including shifts in the ITCZ, can also occur during Indian Ocean Dipole (IOD; Saji et al. 1999; Webster et al. 1999) events. Positive IOD (pIOD) events, characterized by enhanced upwelling and cool SST anomalies off Sumatra and anomalously warm SST in the western Indian Ocean, are associated with a strengthened southwest monsoon over India and anomalous dry conditions over Indonesia. Ding et al. (2010) found pIOD events to be associated with a stronger East Asian summer monsoon due to an anomalously weak Western North Pacific (WNP) subtropical high during the period 1953-1975. In contrast, Guan and Yamagata (2003) found the 1994 IOD event to be associated with anomalous drought conditions over Japan and adjoining East Asia. IOD events also have the potential to modulate the ENSO-Asian monsoon relationship, as shown for Indian rainfall on interannual (e.g., Ashok et al. 2001, 2004; Gadgil et al. 2004; Ashok and Saji 2007) and decadal timescales (Ummenhofer et al. 2011). Indian Ocean conditions thus are important for the Asian monsoon on interannual timescales; furthermore, they have been implicated to play a role in extensive and prolonged drought episodes and been largely overlooked in this regard (Sinha et al. 2011). Therefore, we focus here on Indo-Pacific variability as a whole in its relation to drought across monsoon Asia, given the high degree of connection between Pacific and Indian Ocean variability.

Robust changes in Indo-Pacific climate over recent decades heighten the need for improved understanding of Asian monsoon variability on extended timescales, as well as links to Indo-Pacific conditions on a range of timescales from seasonal, interannual to decadal and beyond. Using monsoon reconstructions from sediments in the Arabian Sea, Anderson et al. (2002) inferred a strengthening of the southwest monsoon over the last 400 years, which they hypothesize could be linked to recent warming and ensuing stronger land-sea thermal contrast with the Eurasian 
continent. Analyzing the water balance over South Asia for a suite of IPCC AR4 models during the twentyfirst century, Prasanna and Yasunari (2011) projected widespread changes to the South Asian monsoon, with rainfall and water balance increases in particular over northwest India. In contrast, using a regional nested climate model, Ashfaq et al. (2009) found a weakening of the South Asian monsoon under enhanced greenhouse gas concentration, owing to increased frequency of break spells. Similarly, more frequent break spells in the Indian monsoon occurred in recent decades, associated with changes in the Somali Jet and enhanced low-level divergence over India that might be related to changes in the circulation across the WNP (Turner and Hannachi 2010). Observed increases in the intensity of the northeast Asian summer monsoon due to enhanced warming in the Indo-Pacific warm pool and increased northward moisture transport are projected to continue in the twentyfirst century (Shin et al. 2011). Large-scale changes in Indo-Pacific climate therefore affect the Asian monsoon, with limited agreement in past trends of Asian monsoon strength in observations and models and large uncertainties surrounding future projections.

The surface Indian Ocean has been warming (e.g., Ihara et al. 2008), with warming rates exceeding those of the other tropical ocean basins. The temperature increase in the Indian Ocean is non-uniform, with the west warming faster than the east, resulting in a pattern of the SST trend reminiscent of a pIOD event. Coral proxy reconstructions of an IOD index for the last 150 years found an intensification of tropical Indian Ocean variability, with enhanced southeasterly wind speeds in the eastern Indian Ocean, increased upwelling off Sumatra, and more frequent IOD events (Abram et al. 2008). A subsurface cooling trend in the eastern Indian Ocean, reflective of a shoaling thermocline, for the period 1960-1999 in a compilation of historical Indian Ocean temperature observations (Alory et al. 2007), as well as an increasing skewness towards pIOD events (Cai et al. 2009), lend further support to this.

In the tropical Pacific, since the mid-nineteenth century a weakening of the zonal sea level pressure (SLP) gradient and the Walker circulation has been observed, consistent with the expected behavior of the tropical atmospheric circulation under anthropogenic climate change (Vecchi et al. 2006). In contrast, Karnauskas et al. (2009) found the zonal SLP gradient in the Pacific to have weakened only in boreal spring, while instead the zonal Pacific SST gradient seems to have strengthened. This disagreement in tropical Pacific behavior to climate change is also reflected in uncertainty in the projected response of ENSO, either being driven by considerations of ocean dynamics or those based on atmospheric energy (Karnauskas et al. 2009). Decadal variability, in particular a shift in Indo-Pacific climate in the mid-1970s, which also affected its relationship with the Asian monsoon systems (Wang et al. 2008b; Ding et al. 2010), complicates such an assessment.

While it is likely that the mean state of the Pacific climate will undergo considerable changes in a warming world, exact changes to ENSO dynamics remain uncertain due to various competing feedbacks in the ocean-atmosphere interaction. Collins et al. (2010) summarize our present understanding of expected changes in ENSO and highlight the importance of an extended record of IndoPacific variability, against which to assess the recent and projected changes. The present study contributes towards this goal by developing an understanding of the physical mechanisms behind the regional drought response across monsoon Asia linked to Indo-Pacific variability during the instrumental period. As such, the study here represents a "proof of concept" for linking Indo-Pacific variability to regional drought patterns in the MADA. In a follow-up study, we will use dominant drought patterns across monsoon Asia in the MADA based on extended tree-ring chronologies to infer Indo-Pacific variability prior to the instrumental record.

The remainder of the paper is structured as follows: Sect. 2 describes the data sets and methods used. In Sect. 3, drought patterns across monsoon Asia during ENSO and IOD events from reconstructions are compared to those based on instrumental data. The variability in drought patterns amongst ENSO and IOD events are assessed in Sect. 4. Section 5 identifies the large-scale circulation anomalies in the Asian monsoon system and regional changes resulting in distinct drought patterns during ENSO and IOD events. Finally, Sect. 6 summarizes our main findings.

\section{Data and methods}

\subsection{Data sets}

To assess the influence of Indo-Pacific variability on regional climate across monsoon Asia, we employ a series of observational and reanalysis data sets, as well as a drought atlas reconstructed from tree-ring chronologies. Details for the various data sets used are given in the following sections.

\subsubsection{Reanalysis data sets}

If not otherwise stated, all variables are monthly and gridded with a spatial resolution of approximately $2.5^{\circ}$ latitude/longitude. The SST data for the period 1877-2005 was taken from the Hadley Centre's HadISST product at $1^{\circ}$ spatial resolution (Rayner et al. 2003). As a measure of 
drought across monsoon Asia, the Dai Palmer Drought Severity Index (PDSI) was used for the period 1877-2005 (Dai et al. 2004). Advantages and drawbacks of the PDSI are summarized by Dai (2011), according to which the 'PDSI measures the departure of moisture balance from a normal condition'. Negative PDSI values reflect drought conditions to varying degrees (e.g. -4 or less indicates extreme drought), while positive PDSI values reflect excess moisture. The large-scale circulation across the IndoPacific region was assessed using data from the National Center for Environmental Prediction (NCEP) and National Center for Atmospheric Research (NCAR) reanalysis (NNR) project. For the period 1877-2005, we used monthly wind data from NNR's twentieth Century Reanalysis Project (Compo et al. 2006). During the first half of this analysis period in particular, available highquality data is very sparse across the Indo-Pacific region. The analysis was therefore repeated for the more recent period post-1948, using the NNR reanalysis (Kalnay et al. 1996; Kistler et al. 2001). The variables assessed for 1948-2005 included moisture flux (integrated below $500 \mathrm{hPa}$ ), velocity potential $\chi$ at $850 \mathrm{hPa}$ and precipitation. The results obtained for precipitation were also compared with those of improved quality for the period 1979-2005 based on the Climate Prediction Center (CPC) Merged Analysis Product (CMAP; Xie and Arkin 1996) and the period 1950-2005 for the Global Precipitation Climatology Centre (GPCC) product (Fuchs et al. 2007). Zhang and Zhou (2011) compared several land-based precipitation products over the global monsoon regions with precipitation anomalies based on Dai et al. (1997). Annual mean GPCC precipitation, its annual range, and leading spatial pattern over the Asian monsoon region compares well with the CRU and Dai-data set. The Tibetan Plateau, however, was found to be an area with lower agreement amongst the data sets, likely due to sparse station coverage (Zhang and Zhou 2011). Sparse data coverage for this region needs to be kept in mind for this study, when comparing observational products with the MADA reconstruction. However, for the large-scale features in precipitation anomalies across temperate and monsoon Asian region investigated here, the intercomparison between CMAP and GPCC data showed results to remain robust across different products and analysis periods (figure not shown). In the remainder of the study, figures therefore present results for the longest record available.

\subsubsection{MADA}

Until recently, only very few exactly dated, high-resolution proxy records have been available for low-latitude land areas of Asia. This situation has improved considerably with the recent development of a comprehensive and robust data base of hydroclimatically-sensitive tree-ring chronologies from across monsoon Asia. Known as the Monsoon Asia Drought Atlas (MADA; Cook et al. 2010), the MADA is a seasonally-resolved, gridded spatial reconstruction of Asian monsoon drought and pluvials over much of the past thousand years. The spatiotemporal information gleaned from the MADA on monsoon failures and other extremes provides a long-term context for recent monsoon variability during the anthropogenic era. The MADA covers large areas of temperate Asia, South Asia, and parts of the Indian Ocean rim countries sensitive to IOD and ENSO variability (including Pakistan, Bhutan, China, Nepal, Thailand, Vietnam, Cambodia, Laos, and Indonesia) spanning much of the past millennium. With a spatial resolution of $2.5^{\circ}$ latitude/longitude, the MADA covers the land area across the domain $61^{\circ}-144^{\circ} \mathrm{E}$ and $9^{\circ} \mathrm{S}-56^{\circ} \mathrm{N}$, as shown in Fig. 1. The reconstruction is based on the June-August (JJA) PDSI and spans the period 1300-2005, though the focus in the present study lies on the analysis period 1877-2005. For further details regarding the methodology of the MADA reconstruction, the reader is referred to Cook et al. (2010, and references therein).

\subsection{ENSO and IOD classification}

To investigate the impact of Indo-Pacific climate variability on regional drought patterns across monsoon Asia, we used composites of the PDSI and large-scale circulation anomalies during years with ENSO and/or IOD events, as the leading modes of Pacific and Indian Ocean variability, respectively. The classification of ENSO and IOD events is based on the methodology described by Meyers et al. (2007) and updated in Ummenhofer et al. (2009). For the period 1877-2006, all years are classified as to the state of the Pacific and Indian Ocean, respectively, resulting in a $3 \times 3$ matrix of possibilities (cf. Auxiliary Table in Ummenhofer et al. 2009). Though statistical in nature, the classification method is firmly based on the ocean dynamics of the equatorial Indo-Pacific that control development of ENSO and IOD events (Meyers et al. 2007). In particular, upwelling in the east of the respective ocean basin is seen as a crucial process for ENSO and IOD events and this is reflected in the classification (cf. Sect. 4) Furthermore, by removing the ENSO signal first, it is designed to identify independent IOD events. In addition to SST indices across the equatorial Indo-Pacific region (i.e. from the Niño-3 region, the Niño warm pool region, the eastern and western Indian Ocean), the classification also uses atmospheric circulation indices, such as the Southern Oscillation index and Darwin sea level pressure. The index time-series were filtered with a 5-month running mean, normalized and shifted to maximize cross-correlation with 
Fig. 1 Long-term June-August mean precipitation $(\mathrm{mm} / \mathrm{month})$ for the region covered by the MADA, based on GPCC data for the period 1950-2005. The boxes indicate the spatial extent of the specific regions analyzed in Fig. 4 for Indonesia (I), Southeast Asia (II), and Eastern China (III)
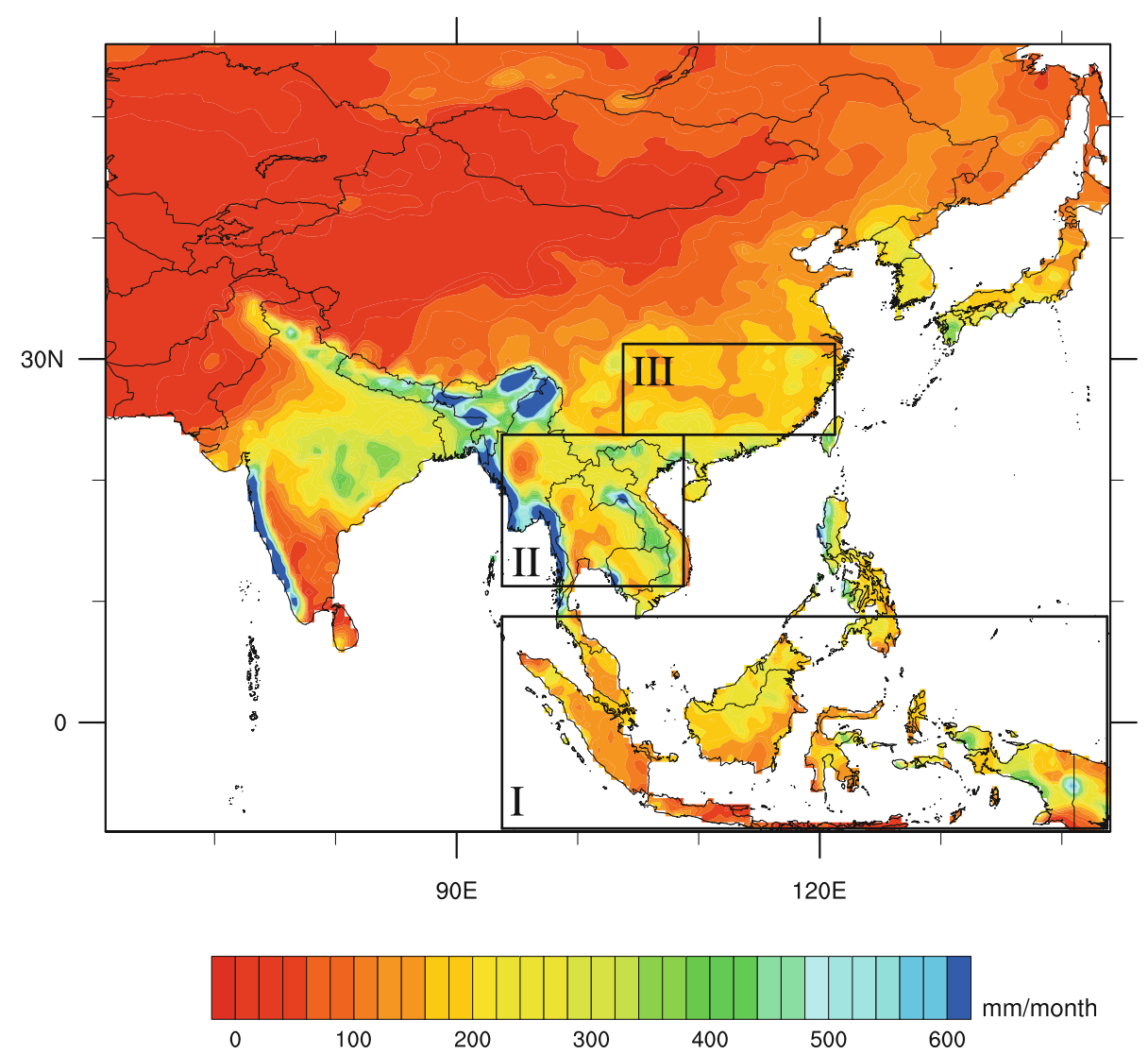

the Niño-3 index to account for phase lags in the response to ENSO. An Empirical Orthogonal Function (EOF) analysis of the six different indices was used to identify the leading mode of variability in the Indo-Pacific climate associated with ENSO. Its time coefficients were used to classify a year as an ENSO event if the coefficients exceeded \pm 1 standard deviation (SD) for two consecutive months during June of the year and February of the following year. Similarly, IOD events were determined by the EOF analysis on the residual index time-series after the signal associated with ENSO had been removed: a year was classified as IOD if the time coefficients exceeded \pm 1 SD for two consecutive months during the main upwelling season off Java-Sumatra during June-December. Our analyses here focus on pIOD, El Niño and coincident pIOD and El Niño events and their respective influence on drought patterns across monsoon Asia due to changes in the large-scale circulation. To identify where composite anomalies (e.g., SST, winds etc.) differ significantly from average conditions, a two-tailed $t$ test has been used throughout the study.

\subsection{Study region}

The spatial extent of the study area is shown in Fig. 1, which depicts the long-term mean of JJA precipitation.
National boundaries have been superimposed, as well as three specific regions highlighted, to facilitate location of regions discussed throughout the manuscript. Figure 1 shows the areas particularly affected by the Indian/South Asian and East Asian monsoon system and highlights some of the spatial heterogeneity in rainfall across the study region that will be referred to in more detail in the following. Particularly prominent are the high-rainfall regions along the west coast of India, Bangladesh, Bhutan, along the coast of Myanmar, and Laos (Fig. 1). Also apparent are the largely semi-arid to arid regions of continental Asia, including western China, Mongolia, Kazakhstan, Uzbekistan, Turkmenistan, Kyrgyzstan, Tajikistan, and Afghanistan. The spatial extent for the three regions analyzed in Fig. 4, i.e. Indonesia (I), Southeast Asia (II), and eastern China (III) is provided as well.

\section{Comparison of MADA and instrumental PDSI}

Drought patterns across monsoon Asia based on reconstructed PDSI from the MADA (Cook et al. 2010) are compared with instrumental PDSI (Dai et al. 2004). The reconstruction focuses on the summer monsoon season and all the following analyses are based on seasonal averages for JJA. The comparison is conducted for the period 
1877-1989, when both data sets are completely independent, as instrumental PDSI is used for the reconstruction in the MADA post-1990 (Cook et al. 2010). Using only the post-1950 period with improved quality in the instrumental PDSI, the comparison was repeated (figure not shown). The results were robust, with the drought patterns for the shorter period closely matching the extended period 1877-1989, albeit with reduced areas of significant anomalies due to the smaller number of events. Therefore, only the results for the comparison over the extended record (1877-1989) are shown. Composite anomalies of PDSI during years classified as El Niño, pIOD, and coincident El Niño with pIOD events are shown in Fig. 2 for the two data sets. Readily apparent is the difference in the magnitude of the PDSI anomalies between the two products (cf. Fig. 2a-c, d-f), with smaller anomalies in the MADA compared to the instrumental PDSI. This is not unexpected, as tree-ring reconstructions typically only capture a fraction of the instrumental variance. Some of the variance loss in the MADA in particular may also be related to the way the search-radii ensembles are combined.

During El Niño events, the MADA shows northern China, eastern Mongolia, the Tien Shan mountains, Kazakhstan, and far western and southern India to be anomalously dry (Fig. 2a). Bangladesh, Indonesia and Southeast Asia also experience anomalous drought conditions, consistent with earlier work, for example in Cambodia (Buckley et al. 2010), Thailand (Buckley et al. 2007),
Myanmar (D'Arrigo et al. 2011), and Indonesia (D'Arrigo et al. 2006). In contrast, anomalous wet conditions occur in Pakistan and Afghanistan, along the eastern seaboard of China, and western Mongolia (Fig. 2a). For instrumental PDSI, anomalous dry conditions for northern and central China, western Himalayas, parts of India, Southeast Asia, and Indonesia agree with drought patterns from the MADA (Fig. 2d). However in the instrumental PDSI, more widespread drought conditions are seen over the Indian subcontinent (Fig. 2d), indicative of the frequent failure of the Indian summer monsoon during $\mathrm{El}$ Niño events (e.g., Krishna Kumar et al. 2006, and references therein). This well-established link between El Niño and the Indian summer monsoon is less well captured by the MADA. This could be related to the limited number of tree-ring chronologies available for the Indian subcontinent (cf. Fig. 1 in Cook et al. 2010). The seasonality in the impact of ENSO on monsoon Asia might also play a role, which is only partially captured by the JJA reconstruction used here. Drought atlas reconstructions for other seasons are still under development. It should also be noted that the instrumental gridded PDSI data set (Dai et al. 2004) used for comparison here is similarly limited by scarce spatial coverage particularly prior to 1950 as highlighted earlier; caution in the interpretation is therefore warranted, as this might affect the results.

Large areas across central Asia, including China, Mongolia, Afghanistan, and Kazakhstan, experience anomalous drought conditions during pIOD events (Fig. 2b, e). In
Fig. 2 Composite PDSI anomalies during (left) El Niño, (middle) pIOD, and (right) cooccurring El Niño and pIOD events. The PDSI anomalies are based on a-c reconstructions from the MADA and d-f instrumental records, both for the June-August months during the period $1877-1989$. The number of members $(\mathrm{N})$ in each category is indicated. The area enclosed by the dashed contours denotes anomalies that are significant at the $80 \%$ confidence level as estimated by a two-tailed $t$ test
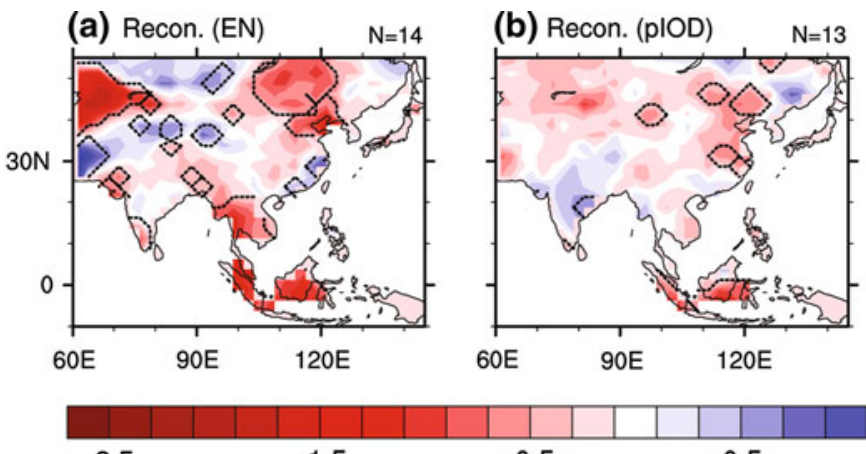

(c) Recon. (EN \& plOD) $\mathrm{N}=5$

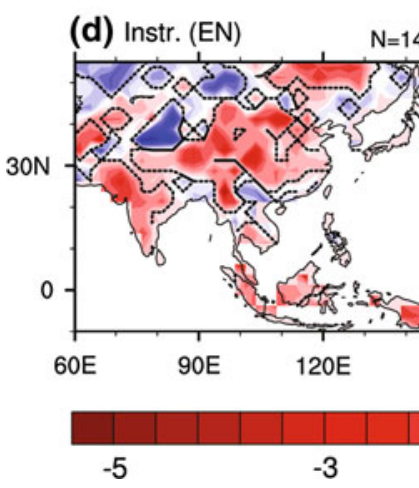

$-0.5$

0.5

1.5

2.5

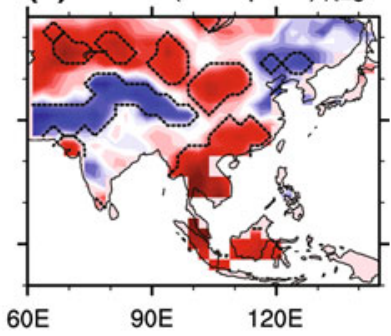

(e) Instr. (plOD)

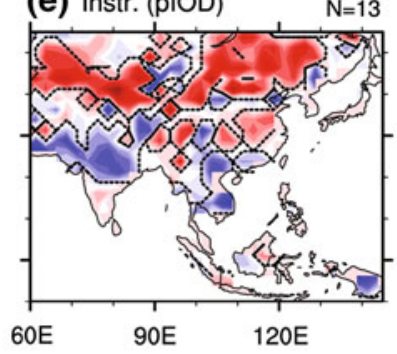

(f) Instr. (EN \& pIOD) $\quad \mathrm{N}=5$

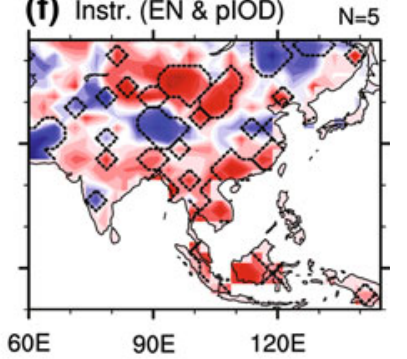

3 
contrast, pIOD events are characterized by enhanced PDSI values over much of the Indian subcontinent (Ummenhofer et al. 2011). These large-scale drought features across Asia are consistent between the MADA and instrumental PDSI. Again, the magnitudes of the anomalies are much smaller for the MADA compared to instrumental values. The two products do not agree well over Southeast Asia, with the MADA indicating anomalous dry and the instrumental PDSI anomalous wet conditions.

Coincident pIOD and El Niño events are characterized by large, broadly consistent PDSI anomalies, with comparable magnitude between the MADA and instrumental PDSI (Fig. 2c, f). With the exception of the Indian subcontinent, southern reaches of the Himalayas and the northeast of China, the majority of the Asian landmass experiences severe drought conditions during co-occurring El Niño and pIOD events. The severity of the drought in large parts seems to be compounded and exacerbated by the phenomena occurring simultaneously. In the MADA, Southeast Asia, Indonesia, central China, and Mongolia show largest negative PDSI anomalies in excess of -2 (Fig. 2c). In the instrumental PDSI, Vietnam, southeastern and central China, parts of Indonesia and northern India show anomalously dry conditions (Fig. 2f). The two products agree closely on the regions with anomalous wet conditions (Pakistan, the foothills of the Himalayas, and northeastern China).

The large-scale drought patterns associated with ENSO and IOD events are in broad agreement between the MADA reconstructed from tree-ring chronologies and the instrumental PDSI across monsoon Asia and into temperate regions (cf. Cook et al. 2010). For a more detailed verification of the MADA for different regions and analysis periods, the reader is referred to the supporting online material in Cook et al. (2010). The following analyses are therefore based on the MADA to provide a first "proof of concept", which can be extended in a follow-up study to exploit the longer drought records available from tree-ring chronologies. The analysis period covers the entire length of the ENSO/IOD classification (1877-2005) that overlaps with the MADA for Figs. 3, 4, 5, 6, 7.

\section{Drought patterns amongst ENSO and IOD events}

Distinct regional drought patterns across monsoon Asia and into temperate regions are apparent during pIOD, El Niño, and coincident events (Fig. 3a-c). The PDSI patterns associated with the three different classifications for the full analysis period 1877-2005 closely resemble those described previously for the period 1877-1989 (cf. Fig. 2). However, the question arises how consistent are the PDSI patterns amongst the composite members of a category?
Therefore, SD of the PDSI anomalies across the composite members is shown in Fig. 3d-f.

For the El Niño composite, consisting of 14 events, low SD of less than 1.2 for much of the Indian subcontinent, Southeast Asia, Indonesia, China, and Mongolia reveal consistent PDSI anomalies during these events (Fig. 3d). In contrast, high SD in excess of 2.5 is seen over Kazakhstan, Afghanistan, the Tien Shan Mountains and extending into western China. This could suggest that the severe drought signal for the region (Fig. 3a) is an inconsistent feature among El Niño events and possibly more dominated by local influences. However, more likely the large SD indicates that, as a response to El Niño, moisture contents in arid central Asia are more variable than those in humid monsoon Asia. This needs to kept in mind when comparing the PDSI between arid and humid regions. Localized increased variability for the PDSI anomalies among El Niño events is also recorded for Myanmar, northwestern Thailand, and northeastern China (Fig. 3d).

The PDSI SD for the 13 pIOD events is low $(<1.2)$ for large parts of northern India, Southeast Asia, Indonesia, China, and Mongolia (Fig. 3e). However, the Himalayas, and western reaches of China and Mongolia are characterized by higher variability, indicative of a variable PDSI signal for the region amongst pIOD events. Amongst the five coincident El Niño and pIOD events localized very low variability $(<0.7)$ is seen for parts of eastern India, Myanmar, Thailand, Indonesia, and northeastern China (Fig. 3f). The spatial pattern of the low variability is largely consistent with the regions experiencing severe drought. In contrast, some of the anomalously wet PDSI signals in parts of Vietnam, southeastern and eastern China, the Himalayas, Pakistan, and Afghanistan show high SD in excess of 2.5 (Fig. 3c, f).

To further assess the consistency of the drought response amongst $\mathrm{El}$ Niño and pIOD events, the PDSI anomalies are analyzed for three specific regions affected by different components of the Asian monsoon system. The three regions are Indonesia, Southeast Asia, and eastern China, with their respective spatial delimitations highlighted by the boxes in Fig. 1.

Figure 4 presents JJA PDSI anomalies in the three different regions for those years classified as El Niño, pIOD, or co-occurring events, with the number of events in each category given as $N$. The PDSI anomaly for a given category is summarized by the box, with the horizontal lines indicating the upper quartile, median, and lower quartile, while the circles represent the actual PDSI anomalies for the individual years in a particular category. To determine whether the composite PDSI anomalies for the three categories differed significantly from zero, a Monte Carlo analysis approach was employed, in which multiple random samples of PDSI anomalies were selected from the 
Fig. 3 Composite reconstructed PDSI (a-c) anomalies and (d-f) standard deviation during (left) El Niño, (middle) pIOD, and (right) co-occurring El Niño and pIOD events for the JuneAugust months for the period 1877-2005. The number of members $(\mathrm{N})$ in each category is indicated. The area enclosed by the dashed contours in a-c denotes anomalies that are significant at the $80 \%$ confidence level as estimated by a two-tailed $t$ test
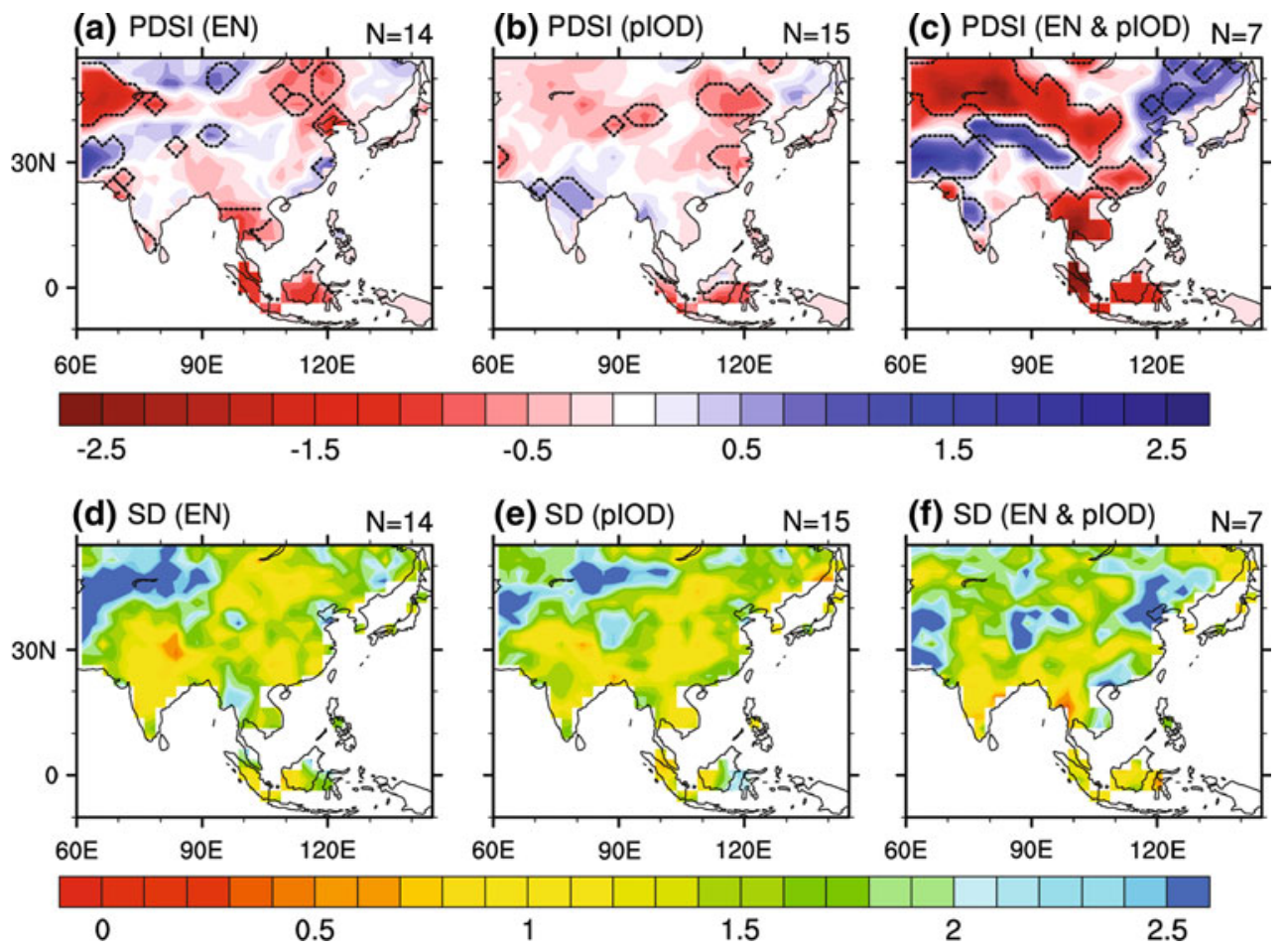

complete set of years 1877-2005 at the respective location as follows: A boot-strapping technique was used to generate an expected distribution of PDSI anomalies based on randomly selected subsets of $N$ number of years taken from the entire distribution of PDSI anomalies at the respective location. To determine significance levels this process was repeated 25,000 times to result in an expected distribution of composite PDSI anomalies based on a given number $(N)$ of years, which is summarized by the error bars in Fig. 4. Where the error bar overlaps with the median PDSI anomaly, the median in a given category does not differ from zero at the $90 \%$ confidence level, as determined by the boot-strapping. This Monte Carlo analysis approach was similarly employed to determine significance levels for monsoon index anomalies in the different categories (cf. Fig. 6b).

During El Niño events, the median PDSI is significantly reduced (close to -1 ) for Indonesia and Southeast Asia, but not eastern China (Fig. 4). Indonesia also records significant reductions in median PDSI during pIOD events, though the spread in the PDSI anomaly is considerably larger than during El Niño events. The PDSI in neither Southeast Asia nor eastern China deviates significantly from 0 during pIOD events. In contrast, co-occurring El Niño and pIOD events are characterized by significant reductions in the median PDSI in all three regions, indicating severe drought conditions (median in excess of -1) in particular for Indonesia and Southeast Asia. The larger spread in the PDSI anomalies in Southeast Asia and eastern China during co-occurring El Niño and pIOD events

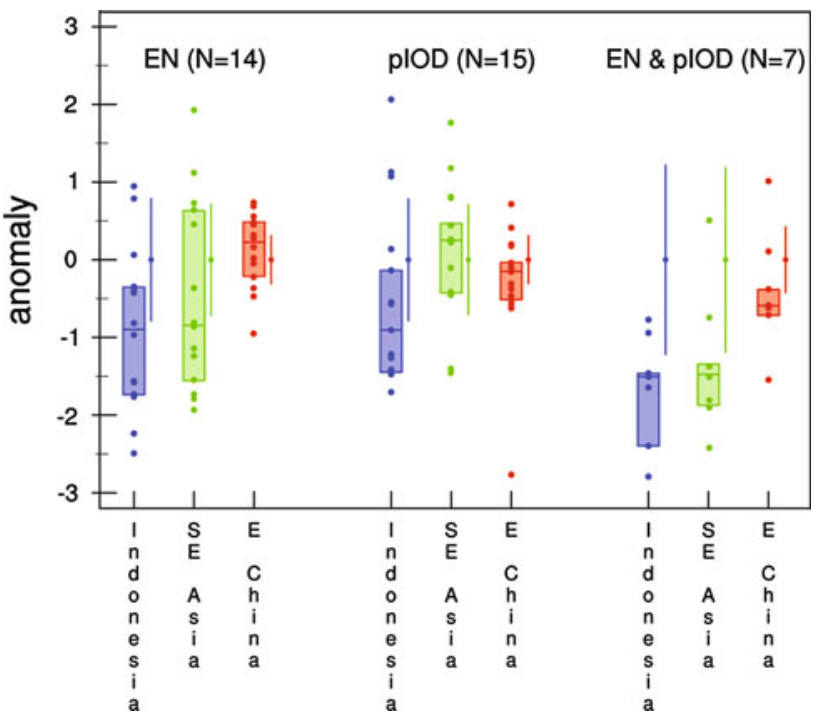

Fig. 4 Reconstructed PDSI for the three regions (Indonesia, Southeast Asia, and Eastern China) shown in Fig. 1 for the June-August months for the period 1877-2005, shown as dots during (left) El Niño, (middle) pIOD, and (right) co-occurring El Niño and pIOD events. The colored boxes are delimited by the upper and lower quartiles, with the middle bar denoting the median in the respective index and category. Error bars indicate the value the median needs to exceed to be significantly different from 0 (at the $90 \%$ confidence level, as estimated by Monte Carlo testing) for the different indices/categories. The number of years $(\mathrm{N})$ in each category is indicated at the top

(Fig. 4) can explain the locally higher SD seen in those regions in Fig. 3f, compared to the more consistent drought signal over Indonesia. 


\section{Drought patterns linked to Indo-Pacific climate anomalies}

\subsection{Anomalous Asian monsoon circulation}

To understand the underlying physical mechanism and dynamics behind the PDSI pattern during El Niño, pIOD, and coincident events, it is of interest to explore how the Asian monsoon during these events is affected by IndoPacific variability more broadly. In Fig. 5, composite anomalies of SST and winds at $850 \mathrm{hPa}$ during JJA are shown for the three categories for the period 1877-2005. SST associated with El Niño events show anomalous warming in excess of $1{ }^{\circ} \mathrm{C}$ in the central and eastern equatorial Pacific, with a classical 'horseshoe' pattern of cold SST in the western equatorial Pacific and in the subtropics (Fig. 5a). The western tropical Indian Ocean is also anomalously warm, while the northwest shelf off Australia records below-average SST.

The pIOD SST pattern is characterized by cold anomalies in excess of $-0.5^{\circ} \mathrm{C}$ in the eastern equatorial Indian Ocean, around the Indonesian Archipelago, parts of the South China Sea, and extending south into the Coral Sea (Fig. 5b). No significant warm SST anomalies are seen in the western Indian Ocean. The SST anomaly pattern for pIOD events is consistent with the emphasis in the classification method placed on upwelling in the east as the key process for IOD development (Meyers et al. 2007). Enhanced upwelling in the eastern Indian Ocean off Java and Sumatra is clearly evident for the pIOD, but not the El Niño events (Fig. 5a, b, Meyers et al. 2007). Furthermore, the removal of the ENSO signal from Indian Ocean data in order to highlight independent events, also contributes towards the reduction of the warm anomaly signal in the west, which can be seen as a response to El Niño (Sinha et al. 2011, and references therein).

SST composites during coincident pIOD and El Niño events show very strong anomalies (well in excess of $\pm 1{ }^{\circ} \mathrm{C}$ ), with cool temperatures in the eastern Indian Ocean and around the Indonesian Archipelago and warm anomalies in the central and eastern Pacific (Fig. 5c). Localized anomalously warm SST anomalies are also observed in the Arabian Sea (Sinha et al. 2011, and references therein).

Large-scale circulation anomalies at the $850 \mathrm{hPa}$ level (Fig. 5d-f) are used, as that is well-suited to explore monsoon dynamics (Webster et al. 1998). Furthermore, several different Asian monsoon indices and their response to ENSO and IOD events are explored. The monsoon indices are as follows, with the details schematically represented in Fig. 6a: Dynamic Indian Monsoon Index (DIMI; Wang and Fan 1999), as the difference in zonal wind at the $850 \mathrm{hPa}$ level between the Arabian Sea $\left(5^{\circ}-\right.$ $\left.15^{\circ} \mathrm{N}, 40^{\circ}-80^{\circ} \mathrm{E}\right)$ and northern India $\left(20^{\circ}-30^{\circ} \mathrm{N}, 70^{\circ}-\right.$ $90^{\circ} \mathrm{E}$ ), which specifically assesses the strength of the monsoon circulation over the Indian subcontinent; South Asian Monsoon Index (SAMI; Goswami et al. 1999), as the difference between low-level $(850 \mathrm{hPa})$ and upper-level (200 hPa) meridional wind more widely over India and Southeast Asia $\left(10^{\circ}-30^{\circ} \mathrm{N}, 70^{\circ}-110^{\circ} \mathrm{E}\right)$; East Asia-WNP Monsoon Index (EAWNP; Wang et al. 2008a), as the difference in zonal wind at the $850 \mathrm{hPa}$ level between Southeast Asia $\left(5^{\circ}-15^{\circ} \mathrm{N}, 90^{\circ}-130^{\circ} \mathrm{E}\right)$ and the East China Sea $\left(20^{\circ}-30^{\circ} \mathrm{N}, 110^{\circ}-140^{\circ} \mathrm{E}\right)$.

Figure $6 \mathrm{~b}$ presents JJA anomalies in the different monsoon indices for those years classified as El Niño, pIOD, or co-occurring events. As detailed before for the PDSI in specific regions (cf. Fig. 4), Monte Carlo analysis was

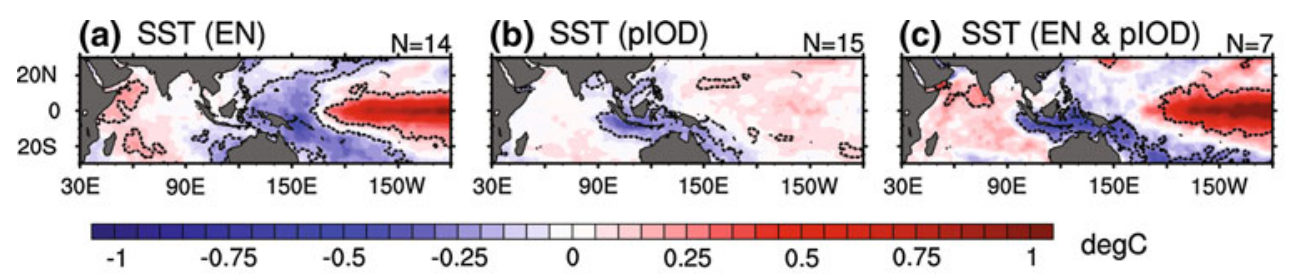

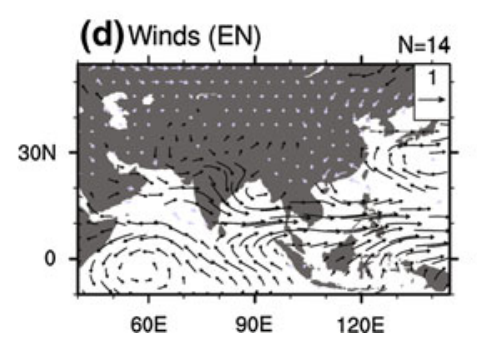

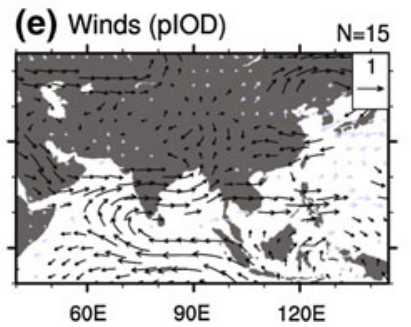

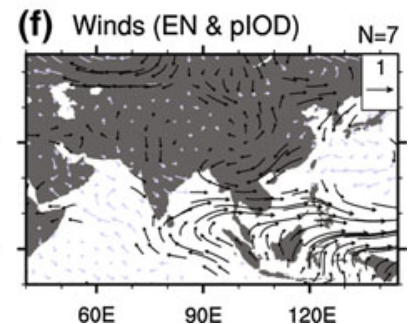

Fig. 5 Composite anomalies during (left) El Niño, (middle) pIOD, and (right) co-occurring El Niño and pIOD events averaged for the June-August months for a-c SST $\left({ }^{\circ} \mathrm{C}\right)$, and $\mathbf{d}-\mathbf{f}$ winds at $850 \mathrm{hPa}(\mathrm{m}$ $\mathrm{s}^{-1}$ ). All anomalies are based on the period 1877-2005. The number of members $(\mathrm{N})$ in each category is indicated. The area enclosed by the dashed contours and the black arrows denote anomalies that are significant as estimated by a two-tailed $t$ test at the following confidence levels: $90 \%$ for SST, and $80 \%$ for winds 


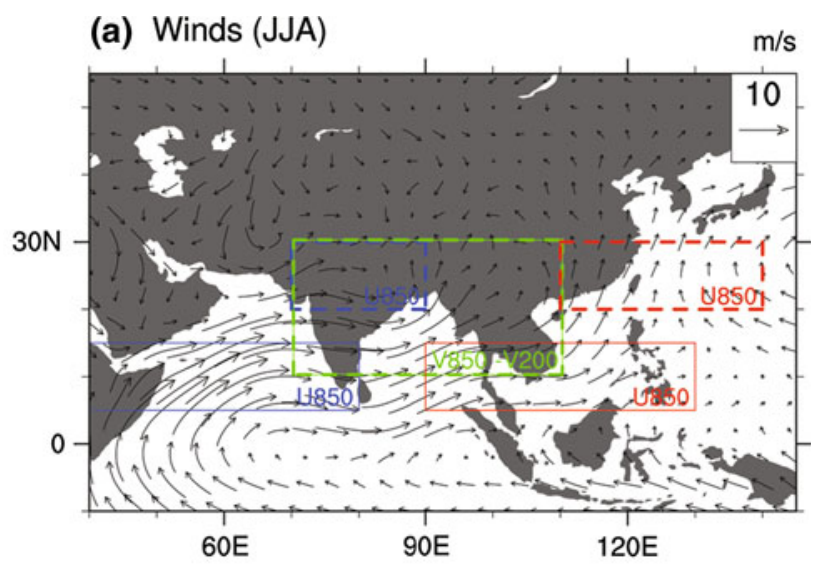

(b) Monsoon indices

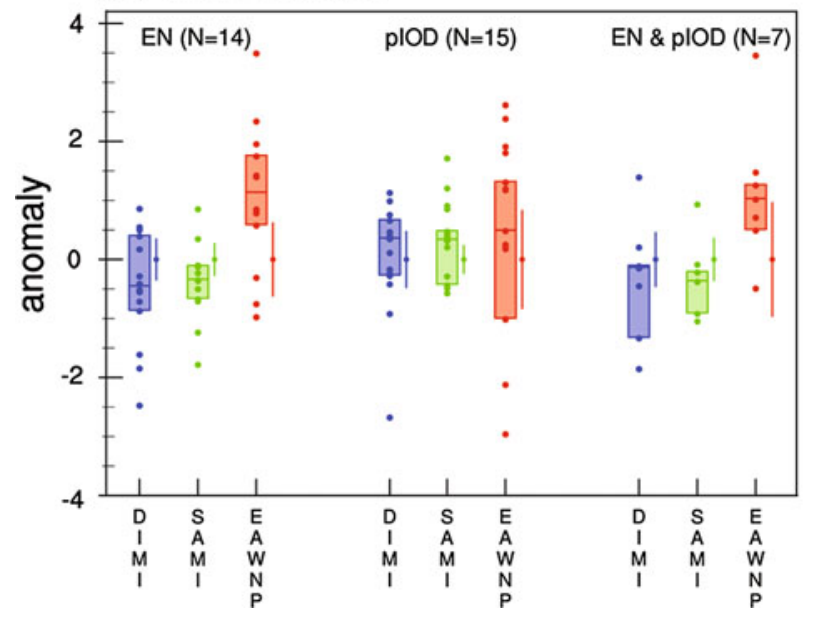

Fig. 6 a Long-term mean winds at the $850 \mathrm{hPa}$ level during JuneAugust for the period 1877-2005. Boxes highlight the areas used for three different monsoon indices: Dynamic Indian monsoon index (blue), South Asian monsoon index (green), and East Asian-Western North Pacific monsoon index (red), with the dashed box indicating the region subtracted from the solid box; variables and atmospheric levels for the indices are given as well. b Anomalies in monsoon indices defined in (a), shown as dots during (left) El Niño, (middle) pIOD, and (right) co-occurring El Niño and pIOD events. The colored boxes are delimited by the upper and lower quartiles, with the middle bar denoting the median in the respective index and category. Error bars indicate the value the median needs to exceed to be significantly different from 0 (at the $80 \%$ confidence level, as estimated by Monte Carlo testing) for the different indices/categories. The number of years $(\mathrm{N})$ in each category is indicated at the top

employed to determine whether a median monsoon index anomaly in a given category differs from 0 at the $80 \%$ confidence level.

El Niño events are characterized by westerly anomalies over the Bay of Bengal, Southeast Asia and the South China Sea and the western Indonesian Archipelago (Fig. 5d); over Indonesia, this weakens the climatologically southeasterly flow during JJA (Fig. 6a). For the Bay of Bengal and South China Sea, a weakening of the climatological southerly flow component is observed. In contrast, the basin-wide anticyclonic circulation over the Indian Ocean is enhanced, with anomalous easterly flow especially over the central and western Indian Ocean. Subsiding motion associated with the shift in the zonal Walker circulation (cf. Fig. 7a) leads to anomalous westerlies and divergent flow over the Indonesian Archipelago (Fig. 5d), accounting for the drought conditions there. Over India and Southeast Asia, the climatological southwesterly monsoon flow is weakened considerably, reflected in a significant reduction in the respective monsoon indices DIMI and SAMI (Fig. 6b), accounting for the drier conditions there. This weakening of the monsoonal circulation during El Niño events is consistent with Krishna Kumar et al. (2006) for the Indian and with Goswami and Xavier (2005) for the South Asian monsoon systems. The eastern China seaboard locally experiences wet anomalies due to a strengthening of the EAWNP monsoon during El Niño events (Figs. 5d, 6b). In contrast, northeastern China is characterized by anomalous continental influences and dry conditions.

During pIOD events, an enhanced SAMI (Fig. 6b) reflects strengthened southwesterly monsoonal flow over India and Southeast Asia (Fig. 5e) and anomalous wet conditions across the region (Fig. 3b). Enhanced southeasterly anomalies dominate over the eastern and central equatorial Indian Ocean, coincident with the cool SST anomalies in the upwelling region off the Java and Sumatra coastline (Fig. 5b). The eastern half of China experiences easterly anomalies during pIOD events, weakening the climatological southwesterly flow, though no significant change in the EAWNP monsoon index is apparent (Fig. 6b). However, the considerable range in the EAWNP monsoon index values during different pIOD events might account for the latter, also supported by the higher SD $(>1.5)$ in the PDSI along the eastern China seaboard during pIOD events (Fig. 3e). Furthermore, decadal changes in the relationship between tropical Indian Ocean SST and the strength of the East Asian summer monsoon, related to the 1970s climate shift in Indo-Pacific climate, might also play a role (Ding et al. 2010): during 1953-1975, they found IOD events to be associated with a stronger East Asian monsoon due to a weaker WNP subtropical high, while this relationship does not hold in recent decades when ENSO's influence on the East Asian monsoon seems to have strengthened.

During coincident El Niño and pIOD events, the climatological southeasterly flow during JJA is opposed by strong westerly circulation anomalies across the eastern Indonesian Archipelago (Fig. 5f), resulting in divergent flow and anomalous dry conditions there. Southeast Asia and eastern China, are dominated by strong northerly anomalies, which is consistent with a significant weakening of the SAMI (Fig. 6b) and the drought signal seen in the 
Fig. 7 Composite anomalies during (left) El Niño, (middle) pIOD, and (right) co-occurring El Niño and pIOD events averaged for the June-August months for a-c $850 \mathrm{hPa}$ velocity potential $\chi\left(\mathrm{m}^{2} \mathrm{~s}^{-1}\right)$, d-f reconstructed PDSI, $\mathbf{g}-\mathbf{i}$ moisture flux (integrated below $\left.500 \mathrm{hPa} ; \mathrm{kg} \mathrm{m}^{-1} \mathrm{~s}^{-1}\right)$, and $\mathbf{j}-\mathbf{l}$ precipitation $(\mathrm{mm}$ month $^{-1}$ ). All anomalies are based on the period 1948-2005. The number of members $(\mathrm{N})$ in each category is indicated. The area enclosed by the dashed contours and the black arrows denote anomalies that are significant as estimated by a two-tailed $t$ test at the following confidence levels: $90 \%$ for $\chi$, and $80 \%$ for PDSI, moisture flux, and precipitation

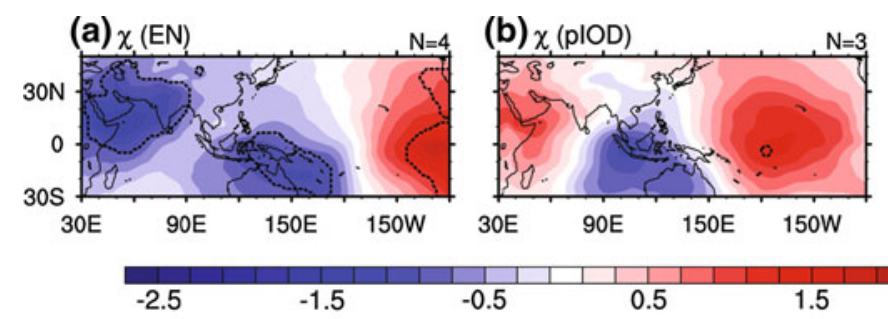

(c) $\chi(E N \&$ pIOD)
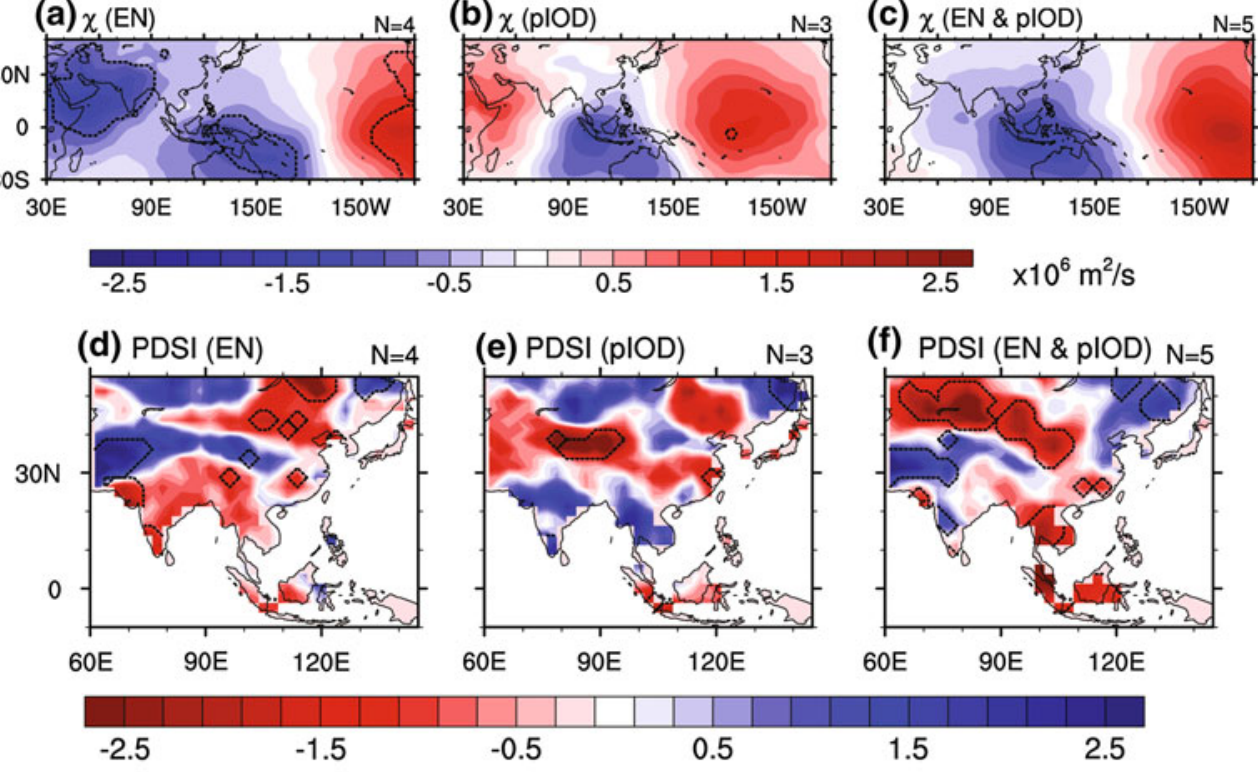

(e) PDSI (plOD)

(f) PDSI (EN \& plOD) $\mathrm{N}=5$
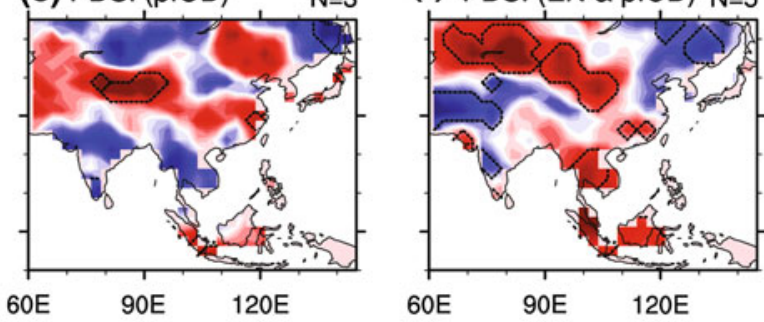

$60 \mathrm{E} \quad 90 \mathrm{E} \quad 120 \mathrm{E}$

$60 \mathrm{E} \quad 90 \mathrm{E} \quad 120 \mathrm{E}$

1.5

0.5

2.5

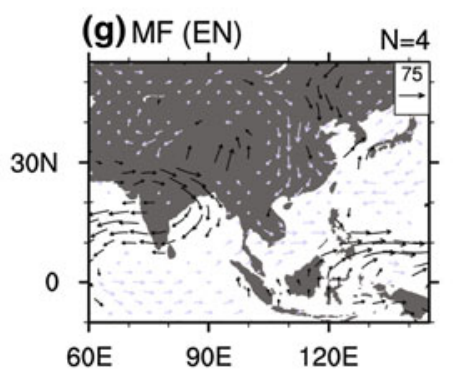

(h) MF (pIOD)

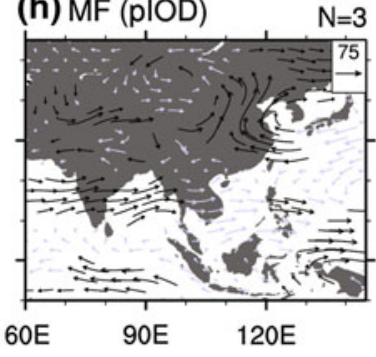

(i) $M F(E N \&$ plOD $) \quad \mathrm{N}=5$
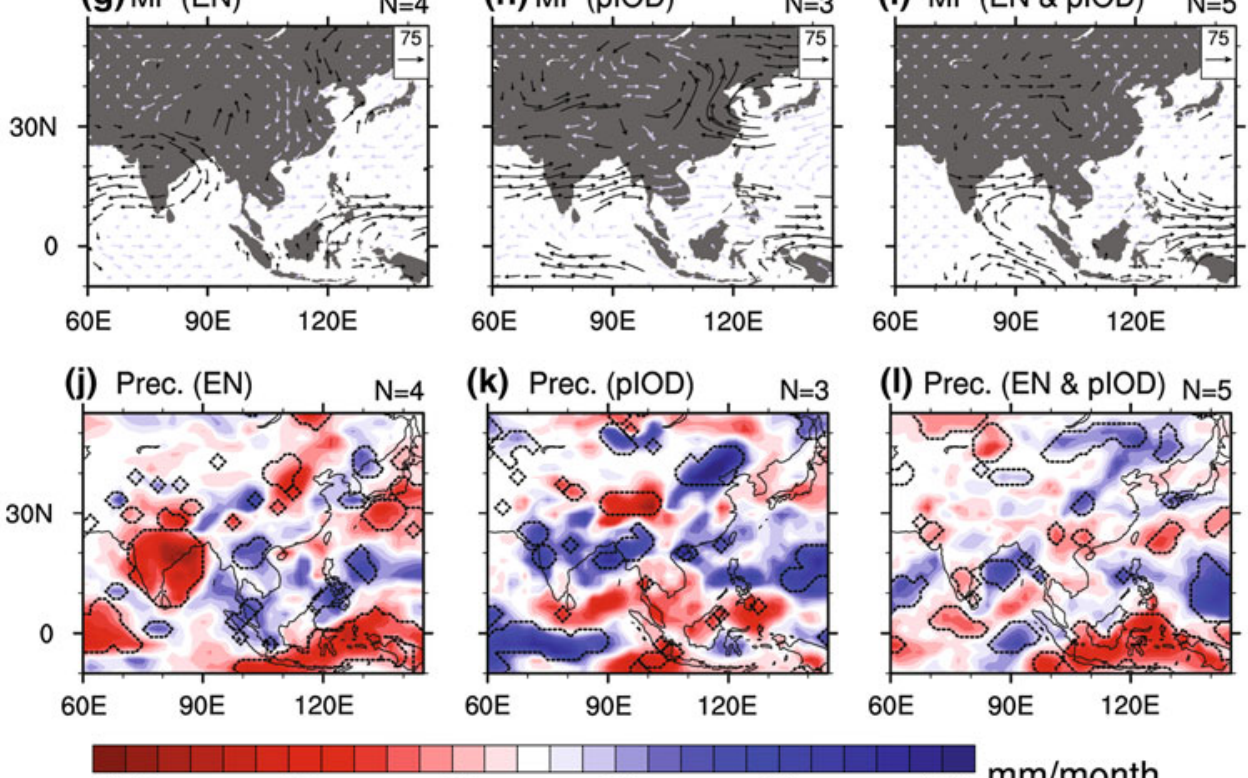

(k) Prec. (plOD) $\mathrm{N}=3$ (I) Prec. (EN \& plOD) $\mathrm{N}=5$

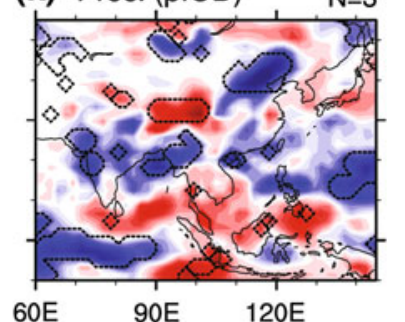
$60 \mathrm{E}$

$90 \mathrm{E}$

$20 \mathrm{E}$

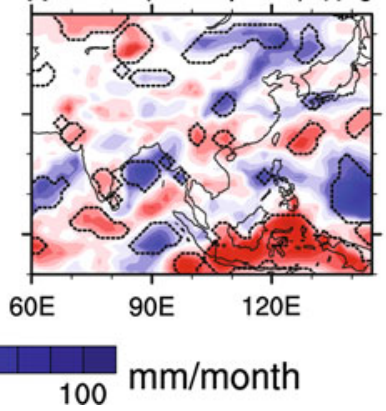

PDSI (Fig. 3c). In contrast, the EAWNP monsoon index does not show a weakening, but rather a slight increase (Fig. 6b), which is inconsistent with the zonal circulation anomalies and the PDSI over eastern China. A large positive outlier in the EAWNP index is likely to account for this, also supported by the increased SD in PDSI during coincident pIOD and El Niño years for eastern China (Fig. 3f). Continental influences seem to characterize much of central Asia, including Mongolia, China, the western reaches of the Himalayas, and Tian Shan Mountain region (Fig. 5f). No significant circulation anomalies are observed for the Indian subcontinent, consistent with an average monsoon season (Ummenhofer et al. 2011).

\subsection{Regional climate anomalies}

Assessment of regional climate anomalies associated with the distinct PDSI patterns in the different ENSO/IOD categories was repeated with reanalysis products for the last five decades. In Fig. 7, results based on JJA for the period 1948-2005 are presented for velocity potential $\chi$ at the $850 \mathrm{hPa}$ level, MADA PDSI, moisture flux, and precipitation. The velocity potential can be regarded as a proxy for the Walker circulation in the tropics, identifying areas of anomalous subsidence and ascent. The moisture flux, calculated as the product of wind vectors and specific humidity, is integrated below $500 \mathrm{hPa}$ and thus represents 
an integrative measure of large-scale moisture transport. It should be noted that the number of events is much reduced due to the shorter analysis period and caution needs to be exercised in the interpretation of Fig. 7.

During El Niño events, the well-known shift in the zonal Walker circulation is apparent in the velocity potential (Fig. 7a), with anomalous ascent in the central and eastern Pacific associated with the warm underlying SST anomalies. In contrast, anomalous subsidence over the western Indian Ocean and the Indonesian Archipelago coincides with dry PDSI conditions over the Indian subcontinent and parts of Southeast Asia, due to a reduction in the onshore moisture flux and reduced precipitation (Fig. 7d, g, j). This is consistent with the well-established relationship between the tropical Pacific and the Indian monsoon, in particular the weakening or failure of the monsoon rains during El Niño (e.g., Krishna Kumar et al. 2006, and references therein). A weakening of this El Niño-Indian monsoon relationship in recent decades has been linked to Eurasian warming (Krishna Kumar et al. 1999) and variations in the location of maximum warming in the equatorial Pacific (Krishna Kumar et al. 2006; Ashok et al. 2007). In contrast, Ummenhofer et al. (2011) attribute variations of the strength of this teleconnection on decadal timescales to Indian Ocean variability over the past century, with more frequent coincident El Niño and pIOD events in recent decades, while Indian monsoon failure was much more common during the period 1911-1942 with frequent independent El Niño events. Krishnan and Sugi (2003) also implicate the different phases of the PDO in changes in the relationship between ENSO and the Indian monsoon, with El Niño events during the warm phase of the PDO more often associated with Indian drought than during the PDO's cold phase.

It is of interest to note that the dominant pattern of drought in the MADA, accounting for $11.5 \%$ of the total variability since 1300 A.D. and identified through distinct EOF analysis (cf. Fig. 3 in Cook et al. 2010), closely resembles the one seen during $\mathrm{El}$ Niño events here (Fig. 7d). Furthermore, the associated SST anomalies across the Indo-Pacific in Cook et al. (2010) compare well with Fig. 5a, indicating a clear distinction in the dominant drought pattern in the MADA between a "pure" El Niño event and one during co-occurring pIOD and El Niño events. Characteristic for the PDSI pattern in both the distinct EOF1 in Cook et al. (2010) and El Niño composite here is the in-phase relationship of the Indian subcontinent and South Asian region in particular, in combination with anomalies of opposite sign to the north.

Anomalous wet conditions at the northern edge of the Indian subcontinent and in the foothills of the Himalayas, as apparent in the PDSI, during El Niño events are not reflected in the precipitation anomalies (Fig. 7d, j). Several rainfall products with improved quality for a more recent period (CMAP for 1979-2005; GPCC for 1951-2004) are used and reflect a similar absence of this high-rainfall region in the Himalayan foothills during JJA in El Niño events (figures not shown). Given the considerably smaller number of events in each category, in particular post-1979, caution in the interpretation is warranted, though. Reduced precipitation and dry PDSI conditions for the Indonesian Archipelago can be associated with divergent wind anomalies (cf. Fig. 5d), also apparent in the moisture flux, due to anomalous subsidence (Fig. 7a). This relationship to ENSO is consistent with earlier findings by D'Arrigo et al. (2006), who found PDSI reconstructed from tree-rings in Java for the period 1787-1988 to correlate significantly with a range of ENSO indices, most notably Niño-3 and Niño-3.4.

Dry conditions in central Asia, including Mongolia and northern China, coincide with more continental influences with anomalous northerly moisture flux and reduced precipitation during El Niño events (Fig. 7d, g, j; e.g., Feng and $\mathrm{Hu}$ 2004; Davi et al. 2010; Fang et al. 2011; Lei and Duan 2011; Li et al. 2011). For drought reconstructions from tree ring records for the period 1520-1993, Davi et al. (2010) found PDSI over Mongolia to be negatively correlated with eastern Pacific SST associated with ENSO. Investigating prolonged dry episodes over northern China for the last 50 years, Lei and Duan (2011) reported reduced moisture transport due to an anomalous Eurasian ridge and northerly circulation anomalies to be associated with enhanced drought frequency during the wet season over northern China. Summer rainfall there is also reduced during El Niño events, though this relationship varies on decadal timescales, most likely due to an interaction between the Indian summer monsoon and regional circulation anomalies (Feng and $\mathrm{Hu} 2004$ ): during periods with co-varying rainfall variability in India and northern China, moisture flux from the Indian monsoon region to northern China is disrupted due to anticyclonic anomalies in midand low-level winds. This is consistent with the high correlation of Indian monsoon precipitation and reconstructed PDSI in Mongolia described in Davi et al. (2010) during such periods, and the PDSI patterns during El Niño events here (Fig. 7d). Fang et al. (2011) reported drought in northwest China to be affected by the early-stage of the Indian summer monsoon, with the period post-1980 characterized by wetter conditions, possibly related to increasing influence from the Indian monsoon and enhanced moisture influx from the Indian Ocean. The role of the Indian Ocean in modulating the teleconnection between ENSO and drought in central Asia is also worth contemplating in this context: i.e the PDSI pattern during co-occurring El Niño and pIOD years (Fig. 7f) reflects the out-of-phase relationship between monsoon rainfall in 
India and northern China that Feng and Hu (2004) discussed for periods when northward moisture convection towards northern China remains unimpeded during El Niño events. The modulation of the El Niño-Indian monsoon relationship on multidecadal timescales by Indian Ocean variability (Ummenhofer et al. 2011), could similarly affect the El Niño-central Asian teleconnection, either directly or indirectly facilitated through the Indian monsoon, as suggested by Feng and Hu (2004) and Fang et al. (2011).

While there is anomalous subsidence over the Indonesian Archipelago during pIOD events (Fig. 7b), the extent and impact is much more local, with locally reduced precipitation and dry PDSI over the west in Sumatra and Borneo (Fig. 7e, k). Enhanced westerly moisture flux and increased precipitation for much of the Indian subcontinent and parts of Southeast Asia are indicative of a strengthened SAMI (cf. Fig. 6b), reflected also in anomalous wet PDSI values over the region. Anomalous drought conditions centered over the Himalayas during pIOD events, as recorded in the PDSI, do not correspond with comparable anomalies in moisture flux. Significant precipitation anomalies occur over Bhutan and northern Myanmar, which is offset to the east of the main PDSI anomaly centered over the Himalayas (Fig. 7e, k). This is likely related to the large variability in the PDSI amongst pIOD events for that region (Fig. 3e), though the small number of events might also be a factor. Consistent with findings by Guan and Yamagata (2003) for the 1994 pIOD event, Japan and adjoining East Asia records drought conditions, as reflected in the PDSI and precipitation anomalies (Fig. 7e, k).

During co-occurring pIOD and El Niño events, subsiding motion is centered over the Indonesian Archipelago and extends northward into monsoon Asia (Fig. 7c). For Indonesia, this is associated with divergent flow, anomalous dry conditions (in excess of -2 in the PDSI) and reduced precipitation (Fig. 7f, k, l). Southeast Asia and the eastern seaboard of China also experience negative PDSI values and a reduced South Asian and EAWNP monsoon, as reflected in the indices (cf. Fig. 6b). Western India is characterized by anomalous wet conditions in the PDSI, partially related to enhanced moisture flux onto the subcontinent in the southern half, though this is not reflected in a strengthened DIMI.

A very strong drought signal is apparent in the PDSI for much of central Asia, including Mongolia, northern and central China during coincident El Niño and pIOD events. Similarly, Davi et al. (2010) found severe drought conditions in Mongolian tree-ring reconstructions in 1789-1793, 1982-1983, 1997-1998 that they linked to 'super ENSOs'. It should be noted that the latter of these events coincide with co-occurring El Niño and pIOD events here and is seen as record event in tree ring reconstructions from other
Indian Ocean rim countries (e.g. in Myanmar; D'Arrigo et al. 2011). Anomalous westerly moisture flux over northern China and Mongolia and reduced precipitation in eastern Kazakhstan (Fig. 7i, 1) could contribute to the drought conditions there. However, the magnitude and spatial extent of the drought signal apparent in the PDSI seems to be inconsistent with the regional circulation anomalies for the period 1948-2005. Given the limitations with the small number of events in some of these categories, it is useful to extend the analysis period beyond the instrumental period, using the reconstructed PDSI from the MADA. Changes over time in the frequency of these drought patterns across monsoon Asia will also be of interest and will be assessed in a separate study.

\section{Summary}

For the period 1877-2005 and focusing on the summer monsoon season (JJA), we explored links between IndoPacific climate variability and drought patterns from the MADA, a network of hydroclimatically sensitive tree-ring chronologies across monsoon and temperate Asia. Using a newly developed classification of ENSO and IOD events (Meyers et al. 2007; Ummenhofer et al. 2009), distinct spatial patterns of drought across Asia were recorded, associated with El Niño, pIOD, and co-occurring El Niño and pIOD events. Intercomparison between the PDSI reconstructions from the MADA and instrumental PDSI during the period 1877-1989, when the two are independent, broadly revealed good agreement in the spatial drought patterns. Regions of disagreement between the two products included India during El Niño and Southeast Asia during pIOD events, with the latter possibly related to the lack of tree ring records for Malaysia, southern Thailand and Sumatra in the MADA. One reason why some of the known relationships between ENSO/IOD and Asian drought patterns are not fully captured could be related to the focus on the JJA season here, while ENSO and IOD, as well as their respective impacts, peak during DecemberFebruary and September-November, respectively. The climate-related response in the tree rings in the MADA is not optimized throughout the network for the JJA season; MADA reconstructions of the PDSI for other seasons are being developed at present and it will be of interest to revisit this in future.

In the MADA, El Niño events are associated with drought over Southeast Asia, Indonesia, northeastern China and locally over India. The additional presence of an pIOD event severely exacerbates El Niño's drought-inducing effect over large areas of monsoon and temperate Asia, including Indonesia, Southeast Asia, eastern China and much of continental Asia north and west of the Himalayas. 
An assessment of the consistency of the PDSI anomaly patterns in the MADA amongst ENSO and IOD events revealed high levels of consistency for much of the Indian subcontinent, Southeast Asia and China, while lower levels of consistency were recorded locally over the Himalayas and the northwestern reaches of the analysis domain.

Drought patterns across monsoon Asia during El Niño, pIOD, and coincident El Niño and pIOD events were related to changes in three different monsoon indices, indicative of the strengths of the Indian, South Asian and EAWNP monsoon systems. During El Niño events, a significant weakening of the Indian/South Asian monsoon circulation, along with a reduction in moisture flux, can account for the drought patterns seen in the Indian subcontinent, Southeast Asia, and Indonesia. A shift in the Walker circulation, along with anomalous subsidence and reduced precipitation over the Indian subcontinent, also contribute to dry conditions during El Niño events. In contrast, pIOD events are associated with a significantly enhanced South Asian monsoon, increased moisture flux, and wet conditions for much of India and Southeast Asia. Severe drought conditions affect Southeast Asia, Indonesia, and eastern China during co-occurring El Niño and pIOD events, associated with a weakened South Asian monsoon and divergent flow anomalies over Indonesia due to anomalous subsidence associated with the shift in the zonal Walker circulation. Severe drought conditions in central Asia north and west of the Himalayas are linked to more continental influences during coincident El Niño and pIOD events, with such severe drought conditions over Mongolia previously attributed to 'super ENSOs' (Davi et al. 2010).

Our assessment of the spatial drought patterns in the MADA associated with ENSO and IOD events highlight the importance of a more nuanced view of Indo-Pacific variability for climate across Asia. In particular, the spatial drought characteristics associated with El Niño events differ considerably between an El Niño event and one cooccurring with an pIOD. Furthermore, a detailed assessment of the large-scale circulation and climate anomalies across the Indo-Pacific region is useful for understanding spatial variations in the drought patterns observed. As such, the results presented here form the first step towards assessing long-term changes in the Asian monsoon system, as seen in drought patterns recorded in hydroclimatically sensitive tree-ring chronologies, in relation to Indo-Pacific climate variability. The study provides insights into the relative influences from Pacific and Indian Ocean variability associated with ENSO and the IOD on drought across monsoon Asia on interannual timescales, as mediated through changes in the monsoon circulation, moisture fluxes, Walker circulation, and precipitation, amongst others. A follow-up study will use this dynamically-based understanding of the spatial characteristics of the drought patterns to assess long-term changes in the Asian monsoon circulation and tropical Indo-Pacific climate. Given the intricate connections between tropical Indo-Pacific climate and the Asian monsoon system, it is important to develop an improved understanding of the potential effects of a warming world on these links (e.g., Li et al. 2010; Yun et al. 2010; Shin et al. 2011) across a range of timescales, as informed by a network of high-quality dendrochronologies from across Asia for the past millennium.

Acknowledgments Use of the following observational and reanalysis products is gratefully acknowledged: PDSI, CMAP, and NCEP/ NCAR reanalysis data provided by NOAA/OAR/ESRL PSD, Boulder, Colorado, USA, through their website http://www.cdc.noaa.gov, and HadISST by the UK Met Office. Development of the MADA was supported by the U.S. National Science Foundation Paleoclimate Program award ATM 04-02474. The work was further supported by the Australian Research Council and the Australian Academy of Science through its Scientific Visits to North America Program. An earlier version of the manuscript benefitted from comments by two anonymous reviewers. Lamont-Doherty Earth Observatory Contribution No. 7570 .

\section{References}

Abram NJ, Gagan MK, Cole JE, Hantoro WS, Mudelsee M (2008) Recent intensification of tropical climate variability in the Indian Ocean. Nat Geosci. doi:10.1038/ngeo357

Alory G, Wijffels S, Meyers G (2007) Observed temperature trends in the Indian Ocean over 1960-1999 and associated mechanisms. Geophys Res Lett 34(L02606). doi:10.1029/2006GL028044

Anchukaitis KJ, Buckley BM, Cook ER, Cook BI, D'Arrigo RD, Ammann CM (2010) Influence of volcanic eruptions on the climate of the Asian monsoon region. Geophys Res Lett 37(L22703). doi:10.1029/2010GL044843

Anderson DM, Overpeck JT, Gupta AK (2002) Increase in the Asian Southwest monsoon during the past four centuries. Science 297:596-599

Ashfaq M, Shi Y, Tung W-W, Trapp RJ, Gao X, Pal JS, Diffenbaugh NS (2009) Suppression of south Asian summer monsoon precipitation. Geophys Res Lett 36(L01704). doi:10.1029/ 2008GL036500

Ashok K, Behera SK, Rao SA, Weng H, Yamagata T (2007) El Niño Modoki and its possible teleconnection. J Geophys Res 112(C11007). doi:10.1029/2006JC003798

Ashok K, Guan Z, Saji NH, Yamagata T (2004) Individual and combined influences of the ENSO and Indian Ocean dipole on the Indian summer monsoon. J Clim 17:3141-3155

Ashok K, Guan Z, Yamagata T (2001) Impact of the Indian Ocean dipole on the relationship between the Indian monsoon rainfall and ENSO. Geophys Res Lett 28(23):4499-4502

Ashok K, Saji NH (2007) On the impacts of ENSO and Indian Ocean dipole events on sub-regional Indian summer monsoon rainfall. Nat Hazards 42(2):273-285

Bordoni S, Schneider T (2008) Monsoons as eddy-mediated regime transitions of the tropical overturning circulation. Nat Geosci 1:515-519

Buckley BM, Palakit K, Duangsathaporn K, Sanguantham P, Prasomsin P (2007) Decadal scale droughts over northwestern Thailand over the past 448 years: links to the tropical Pacific and Indian Ocean sectors. Clim Dyn 29:63-71 
Buckley BM et al (2010) Climate as a contributing factor in the demise of Angkor, Cambodia. Proc Nat Acad Sci 107(15): 6748-6752

Cai W, Cowan T, Sullivan A (2009) Recent unprecedented skewness towards positive Indian Ocean dipole occurrences and their impact on Australian rainfall. Geophys Res Lett 36(L11705). doi:10.1029/2009GL037604

Charles CD, Hunter DE, Fairbanks RG (1997) Interaction between ENSO and the Asian monsoon in a coral record of tropical climate. Science 277:925-928

Chou C, Tu J-Y, Yu J-Y (2003) Interannual variability of the Western North Pacific summer monsoon: differences between ENSO and non-ENSO years. J Clim 16:2275-2287

Collins $M$ et al (2010) The impact of global warming on the tropical Pacific and El Niño. Nat Geosci 3:391-397

Compo GP, Whitaker JS, Sardeshmukh PD (2006) Feasibility of a 100 -year reanalysis using only surface pressure data. Bull Am Meteorol Soc 87:175-190

Cook ER, Anchukaitis KJ, Buckley BM, D’Arrigo RD, Jacoby GC, Wright WE (2010) Asian monsoon failure and megadrought during the last millennium. Science 328:486-489

Dai A (2011) Drought under global warming: a review. WIREs Clim Change 2:45-65

Dai A, Fung I, Genio A (1997) Surface observed global land precipitation variations during 1900-1988. J Clim 10:2943-2962

Dai A, Trenberth KE, Qian T (2004) A global data set of Palmer drought severity index for 1870-2002: relationship with soil moisture and effects of surface warming. $\mathrm{J}$ Hydrometeorol 5:1117-1130

D'Arrigo R, Allan R, Wilson R, Palmer J, Sakulich J, Smerdon JE, Bijaksana S, Ngkoimani LO (2008) Pacific and Indian Ocean climate signals in a tree-ring record of Java monsoon drought. Int J Climatol 28:1889-1901

D’Arrigo R, Palmer J, Ummenhofer CC, Kyaw NN, Krusic P (2011) Three centuries of Myanmar monsoon climate variability inferred from teak tree rings. Geophys Res Lett 38(L24705). doi: 10.1029/2011GL049927

D'Arrigo R, Wilson R, Tudhope A (2009) The impact of volcanic forcing on tropical temperatures during the past four centuries. Nat Geosci 2:51-56

D’Arrigo R et al (2006) Monsoon drought over Java, Indonesia, during the past two centuries. Geophys Res Lett 33(L04709). doi:10.1029/2005GL025465

Davi N, Jacoby G, Fang K, Li J, D’Arrigo R, Baatarbileg N, Robinson D (2010) Reconstructing drought variability for Mongolia based on a large-scale tree ring network: 1520-1993. J Geophys Res 115(D22103). doi:10.1029/2010JD013907

Ding R, Ha K-J, Li J (2010) Interdecadal shifts in the relationship between the East Asian summer monsoon and the tropical Indian Ocean. Clim Dyn 34:1059-1071

Fang K, Gou X, Chen F, Li J, Zhou F, Li Y (2011) Covariability between tree-ring-based precipitation reconstructions in Northwest China and the sea-surface temperature of the Indian and Pacific Oceans. Clim Res 49:17-27

Feng S, Hu Q (2004) Variations in the teleconnection of ENSO and summer rainfall in Northern China: a role of the Indian summer monsoon. J Clim 17:4871-4881

Fuchs T, SU, Rudolf B (2007) Global precipitation analysis products of the GPCC. Tech. rep., global precipitation climatology centre (GPCC), Deutscher Wetterdienst, Offenbach a. M., Germany, $10 \mathrm{pp}$

Gadgil S (2003) The Indian monsoon and its variability. Annu Rev Earth Planet Sci 31:429-467

Gadgil S, Vinayachandran PN, Francis PA, Gadgil S (2004) Extremes of the Indian summer monsoon rainfall, ENSO and equatorial
Indian Ocean oscillation. Geophys Res Lett 31(L12213). doi: 10.1029/2004GL019733

Goswami BN, Krishnamurthy B, Annamalai H (1999) A broad-scale circulation index for interannual variability of the Indian summer monsoon. Q J R Meteorol Soc 125:611-633

Goswami BN, Xavier PK (2005) ENSO control on the south Asian monsoon through the length of the rainy season. Geophys Res Lett 32(L18717). doi:10.1029/2005GL023216

Guan Z, Yamagata T (2003) The unusual summer of 1994 in East Asia: IOD teleconnections. Geophys Res Lett 30. doi:10.1029/ 2002GL016831

Ihara C, Kushnir Y, Cane MA (2008) Warming trend of the Indian Ocean SST and Indian Ocean Dipole from 1880 to 2004. J Clim 21:2035-2046

Kalnay E et al (1996) The NCEP/NCAR 40-year reanalysis project. Bull Am Meteorol Soc 77:437-471

Karnauskas KB, Seager R, Kaplan A, Kushnir Y, Cane MA (2009) Observed strengthening of the zonal sea surface temperature gradient across the equatorial Pacific Ocean. J Clim 22: $4316-4321$

Kistler R et al (2001) The NCEP-NCAR 50-year reanalysis: monthly means CD-rom and documentation. Bull Am Meteorol Soc $82: 247-267$

Krishna Kumar K, Rajagopalan B, Cane MA (1999) On the weakening relationship between the Indian monsoon and ENSO. Science 284:2156-2159

Krishna Kumar K, Rajagopalan B, Hoerling MP, Bates G, Cane M (2006) Unraveling the mystery of Indian monsoon failure during El Niño. Science 314:115-119

Krishnan R, Sugi M (2003) Pacific Decadal Oscillation and variability of the Indian summer monsoon rainfall. Clim Dyn 21:233-242

Lei Y, Duan A (2011) Prolonged dry episodes and drought over China. Int J Climatol 31:1831-1840

Li H, Dai A, Zhou T, Lu J (2010) Responses of East Asian summer monsoon to historical SST and atmospheric forcing during 1950-2000. Clim Dyn 34:501-514

Li Q, Nakatsuka T, Kawamura K, Liu Y, Song H (2011) Hydroclimate variability in the North China Plain and its link with El Niño-Southern Oscillation since 1784 A.D.: insights from treering cellulose $\delta^{18} \mathrm{O}$. J Geophys Res 116. doi:10.1029/ 2011JD015987

Meehl GA, Hu A (2006) Megadroughts in the Indian monsoon region and southwest North America and a mechanism for associated multidecadal Pacific sea surface temperature anomalies. J Clim 19:1605-1623

Meyers G, McIntosh P, Pigot L, Pook M (2007) The years of El Niño, La Niña and interactions with the tropical Indian Ocean. J Clim 20:2872-2880

Prasanna V, Yasunari T (2011) Simulated changes in the atmospheric water balance over South Asia in the eight IPCC AR4 coupled climate models. Theoret Appl Climatol 104:139-158

Rasmusson EM, Carpenter TH (1983) The relationship between eastern equatorial Pacific sea surface temperatures and rainfall over India and Sri Lanka. Mon Weather Rev 111:517-528

Rayner NA, Parker DE, Horton EB, Folland CK, Alexander LV, Rowell DP (2003) Global analyses of SST, sea ice and night marine air temperature since the late nineteenth century. J Geophys Res 108(4407). doi:10.1029/2002JD002670

Ropelewski CF, Halpert MS (1987) Global and regional scale precipitation patterns associated with the El Niño/Southern Oscillation. Mon Weather Rev 398:320-323

Saji NH, Goswami BN, Vinayachandran PN, Yamagata T (1999) A dipole mode in the tropical Indian Ocean. Nature 401:360-363

Shin S-I, Sardeshmukh PD, Yeh S-W (2011) Sensitivity of the northeast Asian summer monsoon to tropical sea surface 
temperatures. Geophys Res Lett 38. doi:10.1029/2011GL049391

Sikka DR (1980) Some aspects of the large scale fluctuations of summer monsoon rainfall over India in relation to fluctuations in the planetary and regional scale circulation parameters. Proc Indian Acad Sci 89:179-195

Sinha A, Stott L, Berkelhammer M, Cheng H, Edwards RL, Buckley B, Aldenderfer M, Mudelsee M (2011) A global context for megadroughts in monsoon Asia during the past millennium. Quat Sci Rev 30:47-62

Turner AG, Hannachi A (2010) Is there regime behavior in monsoon convection in the late 20th century? Geophys Res Lett 37(L16706). doi:10.1029/2010GL044159

Ummenhofer CC, England MH, McIntosh PC, Meyers GA, Pook MJ, Risbey JS, Sen Gupta A, Taschetto AS (2009) What causes Southeast Australia's worst droughts? Geophys Res Lett 36(L04706). doi:10.1029/2008GL036801

Ummenhofer CC, Sen Gupta A, Li Y, Taschetto AS, England MH (2011) Multi-decadal modulation of the El Niño-Indian monsoon relationship by Indian Ocean variability. Environ Res Lett 6. doi: 10.1088/1748-9326/6/3/034006

Vecchi GA, Soden BJ, Wittenberg AT, Held IM, Leetmaa A, Harrison MJ (2006) Weakening of tropical Pacific atmospheric circulation due to anthropogenic forcing. Nature 441:73-76

Wahl E, Morrill C (2010) Toward understanding and predicting monsoon patterns. Science 328:437-438

Wang B, Fan Z (1999) Choice of south Asian summer monsoon indices. Bull Am Meteorol Soc 80:629-638
Wang B, Wu Z, Li J, Liu J, Chang C-P, Ding Y, Wu G (2008) How to measure the strength of the East Asian summer monsoon. J Clim 21:4449-4463

Wang B, Yang J, Zhou T, Wang B (2008) Interdecadal changes in the major modes of Asian-Australian monsoon variability: strengthening relationship with ENSO since the late 1970s. J Clim 21:1771-1789

Webster PJ, Magana VO, Palmer TN, Shukla J, Tomas RA, Yanai M, Yasunari T (1998) Monsoons: processes, predictability, and the prospects for prediction. J Geophys Res 103(C7):14451-14510

Webster PJ, Moore AM, Loschnigg JP, Leben RR (1999) Coupled ocean-atmosphere dynamics in the Indian Ocean during 1997-98. Nature 401:356-360

Xie P, Arkin PA (1996) Analyses of global monthly precipitation using gauge observations, satellite estimates, and numerical model predictions. J Clim 9:840-858

Yadav RR (2011) Long-term hydroclimatic variability in monsoon shadow zone of western Himalaya, India. Clim Dyn 36:1453-1462

Yun K-S, Ha K-J, Wang B (2010) Impacts of tropical ocean warming on East Asian summer climate. Geophys Res Lett 37 (L20809). doi:10.1029/2010GL044931

Zhang L, Zhou T (2011) An assessment of monsoon precipitation changes during 1901-2001. Clim Dyn 37:279-296

Zhang Pet al (2008) A test of climate, sun, and culture relationships from an 1810-year Chinese cave record. Science 322(5903):940-942 